Susanne Dammann · Gattung und Einzelwerk im symphonischen Frühwerk Čajkovskijs 


\author{
Susanne Dammann
}

\title{
Gattung und Einzelwerk im symphonischen Frühwerk Cajkovskijs
}

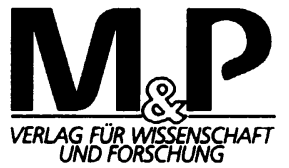


Dissertation

zur Erlangung des Doktorgrades

der Philosophischen Fakultät

der Christian Albrecht Universität

zu Kiel

Referent:

Prof. Dr. Friedhelm Krummacher

Korreferent:

Prof. Dr. Bernd Sponheuer

Tag der mündlichen Prüfung:

16. 12.1992

Zur Vervielfältigung genehmigt:

Dekan:

Prof. Dr. Hubertus Menke

Die Deutsche Bibliothek - CIP-Einheitsaufnahme

\section{Dammann, Susanne:}

Gattung und Einzelwerk im symphonischen Frühwerk Čajkovskijs / Susanne Dammann.

- Stuttgart: M und P, Verl. für Wiss. und Forschung, 1996

Zugl.: Kiel, Univ., Diss., 1992

ISBN 978-3-476-45155-2

ISBN 978-3-476-45155-2

ISBN 978-3-476-04251-4 (eBook)

DOI 10.1007/978-3-476-04251-4

Dieses Werk ist einschließlich aller seiner Teile geschützt. Jede Verwertung außerhalb der engen Grenzen des Urheberrechtsgesetzes ist ohne Zustimmung des Verlages unzulässig und strafbar. Das gilt insbesondere für Vervielfältigungen, Übersetzungen, Mikroverfilmungen und Einspeicherung in elektronischen Systemen.

M \& P Verlag für Wissenschaft und Forschung ein Verlag der J.B. Metzlerschen Verlagsbuchhandlung und Carl Ernst Poeschel Verlag GmbH in Stuttgart

C 1996 Springer-Verlag GmbH Deutschland

Ursprünglich erschienen bei J.B. Metzlersche Verlagbuchhandlung und Carl Ernst Poeschel Verlag GmbH 1996 


\section{INHALT}

Vorwort

Erster Teil Probleme mit Čajkovskij

Erstes Kapitel: Forschungsstand und Forschungsperspektiven

Zweites Kapitel: Čajkovskij und Čajkovskij-Rezeption zwischen "Universalitätsgedanke" und "nationalrussischer Schule"

1. Entstehung und Anspruch auf eine "nationale" Schule bei den Publizisten des Petersburger Kreises und die Vermittlung mit der gesamteuropäischen Tradition: Grundlagen und Aporien von Čajkovskijs "Zwischenstellung"

Exkurs I: Die Entfaltung des historischen Denkens in Rußland und die Konfrontation mit dem deutschen Universalismusanspruch

2. Der Vermittlungsgedanke aus entgegengesetzter Perspektive: Hanslicks, Sittards, Kretzschmars und Laroš' Urteile über Čajkovskij und ihre Grundlagen

3. Čajkovskij und die "Schumannsche Zeit": zum Verhältnis von "Programm" und Autobiographie

Zweiter Teil Dimensionen der frühen Instrumentalmusik Čajkovskijs

Drittes Kapitel: Kompositorische Strukturen der 1. Sinfonie G-Moll op. $13(1866 / 1874)$

1. Der Kopfsatz der 1. Sinfonie G-Moll, op. 13

Exkurs II: Ausgewählte Studienarbeiten Čajkovskijs aus den Jahren am

St. Petersburger Konservatorium

1.1. Die Komplementärthematik des Hauptsatzes

Exkurs III: Parallelen zur Gestaltung von Sektionen in der Ouvertüre Groza [Das Gewitter] von 1864

1.2. Die Gestaltung des Seitensatzes vor der Umarbeitung

1.3. Der Seitensatz in der Fassung von 1874

2. Die Zuspitzung der Komplementärthematik in der Durchführung

3. Die Reprise als dynamisierte Exposition 
4. Die Coda als Schlußreflexion auf die komplementärthematische Anlage des Hauptsatzes

Viertes Kapitel: Exkurse über einige frühe Instrumentalwerke Čajkovskijs (1873-75)

Exkurs IV: Sechs Stücke über ein Thema, op. 21 (1873) 225

Exkurs V: 2. Streichquartett F-Dur, op. 22 (1874) 237

Exkurs VI: Das Verhältnis zwischen den Binnen- und Ecksätzen. Überlegungen zur fünfsätzigen Konzeption der 3. Sinfonie D-Dur, op. 29 (1875)

Fünftes Kapitel: Rhythmisch-motivisch stilisierte Charaktere und thematische Einheit in der 4. Sinfonie F-Moll, op. 36 (1876-1877)

Einführende Überlegungen

1. Die Funktion des "Andante sostenuto" als "Strukturgenerativ" des Kopfsatzes

2. Gestalt und Verlauf des Kopfsatzes $\quad 308$

2.1. Materiale Kontinuität und Charakterwandel: der Verlauf des Hauptsatzes 308

2.2. Der Charakterkontrast des Seitensatzes und seine Herleitung durch

Thementransformation

3. Die Durchführung als Brennspiegel der Exposition

4. Der Verlauf der Reprise und seine Konsequenzen: die Notwendigkeit eines zyklischen Satzkalküls

5. Die Satzcoda als zweite Durchführung in äußerster Zuspitzung

Exkurs VII: Die Binnensätze im zyklischen Kontext des Werkes

6. Die Reflexion des "Finalproblems" oder der Rückgriff auf das

"Andante sostenuto" im Finale der 4. Sinfonie op. 36

Schlußbemerkungen

\section{Anhang}

Bibliographie Raisonnée 


\section{Vorwort}

Die vorliegende Arbeit stellt die überarbeitete Fassung der Dissertation dar, die im Winter 1992 von der Philosophischen Fakultät der Christian-Albrechts-Universität Kiel angenommen wurde.

Mein Dank gilt vor allem meinem akademischen Lehrer und Doktorvater Prof. Dr. Friedhelm Krummacher für die skrupulös angelegte Vermittlung seines fachlichen Anliegens sowie dafür, daß meine Gedanken und ihre sprachliche Gestaltung kritisch geprüft und gefördert wurden. Ferner danke ich Prof. Dr. Bernd Sponheuer, daß er die Arbeit engagiert untersuchte und Verbesserungsvorschläge machte, sowie Prof. Dr. Heinrich Wilhelm Schwab.

Mein Dank gehört auch der freundlichen Bereitschaft von Prof. Dr. Thomas Kohlhase (Tübingen), daß er mir zu Beginn meiner Dissertation Einblick in ungedruckte Typoskripte gewährt hat, die sich in seinem Privatbesitz befinden; auch für entgegenkommende Gesprächsbereitschaft habe ich zu danken.

Außerdem förderte Prof. Dr. Helmut G. Walther (Jena) meine Arbeit sehr durch seine Aufgeschlossenheit für meine Fragestellung sowie durch sein lebhaftes Interesse an der Čajkovskij-Rezeption. Für seine stets aufmunternde Teilnahme am Werdegang meiner Arbeit bin ich ihm sehr dankbar.

$\mathrm{Da} ß$ ich während meiner Aufenthalte in Rußland auch Autographe von Pëtr Il'ič Čajkovskij habe einsehen dürfen, danke ich der großzügigen Unterstützung von Dr. Polina Efimovna Vajdman, der Archivarin des Čajkovskij-Hausmuseums in Klin (Moskauer Region), sowie dem freundlichen Entgegenkommen der Direktorin des Archivs, Galina Ivanovna Belonovič.

Ich denke sehr gerne an die besondere Arbeitsatmosphäre im letzten Wohnsitz des Komponisten zurück, aber auch an die offenen und anregenden Gespräche über Čajkovskijs Leben und Werk.

Schließlich möchte ich mich noch bei den Freunden bedanken, die mir während meiner Dissertation auf die verschiedenste Art und Weise zur Seite gestanden haben: Dr. Claus-Peter Becke (Flensburg), Elena Dormann (Frankfurt), Susanne 
Hockling (Bonn/Stuttgart), Renate Meyer-Reil (Kiel), Dr. Dorothea Scholl (Tübingen/Kiel) sowie PD Dr. Henning Unverhau (Kiel).

Die Arbeit widme ich dem Andenken meines Vaters und meiner Mutter.

Preetz, im Frühjahr 1995

Susanne Dammann 